\title{
The Register Restraint on Characteristics in Chinese Text ${ }^{*}$
}

\author{
TIAN Ran \\ Beijing Language and Culture University, Beijing, China
}

\begin{abstract}
Syntactic expressions in different texts are varied. They are restricted by registers, which are reflected in three aspects: differences in spoken text and written text, narrative text and non-narrative text, children text and adults text. In another word, the external form of Chinese text is restricted by occasions and conditions in which the language is used. Chinese text characteristic is the foundation of text teaching as a second language, but the reserch about Chinese text is rather not enough. This paper has practical value for teaching Chinese as a second language.

Keywords: textual characteristics, register restraint, style differences, genre differences, acquisition mode differences
\end{abstract}

\section{Introduction}

It is a common view that Chinese text teaching as a second language is quite important, espeicially in middle-high level for Chinese learners, Chinese text characteristic is the foundation of text teaching, generally speaking. But the reserch about Chinese text is rather not enough. What is the Chinese text characteristic? What is the difference between different types of texts? That is the reason why the paper is written.

Systemic Functional Linguistics believes that the register is the range of occasion or field the language is used, and three main contextual factors determine the register: field of text, mode of text, and tenor of text (ZHU, 1987).

Field of text includes technical terminology like commercial language, linguistic terminology, and non-technical terms like daily conversation; mode of text includes spoken language and written language (which is usually termed as "style" by scholars of Chinese grammar); tenor of text includes narrative and non-narrative (which is called "genre" by Chinese grammar scholars), also includes formal style and informal style.

Systemic Functional Linguistics holds a view that there are different textual variants in different tenor of text and field of text. For example, distinctive text characteristics can be naturally shown in various texts such as news broadcasts, conversation with children, oral narration, etc.

In the following passage, based on the above theory and the pedagogic requirements of teaching Chinese as a second language, the author will analyze the differences of generative form of Chinese text in different contexts - the register restraint on textual expressions, including restraint on words organization and syntactic sentence.

Spoken/written text in style, narrative/non-narrative text in genre, and children/adults text in acquirers will be analyzed in this paper.

\footnotetext{
* Ministry of Education of China "Humanities and Social Science Planning Fund Item". Item number: 14YJA740031. TIAN Ran, professor, master, Intensive Institute of Chinese Language Teaching, Beijing Language and Culture University.
} 


\section{The Restraint on Style Differences}

The concept "Style" raises much dispute in the field of rhetoric in China. Some study it from textural perspective (CHEN, 1979), some from the behavioral angle (LIU, 1994) and other scholars have shown their view in its definition (X. LI, 2005). Some think that "Style" is the most original, essential linguistic means and mechanism to realize direct human communication (FENG, 2011).

Its concept will not be discussed in this paper but the differences of two styles on words organization and syntactic representation from the perspective of current situation of teaching Chinese as a second language, while spoken language and written language are classified as subordinate words of Style.

First, look at the examples of FENG Sheng-li (2011):

Example (1) a. Today, my father mai and du a book to me. (mai and du, Chinese pronunciation, to buy and read)

b. Yesterday, the leader asked people to mai and kan the new version of the Constitution. (to buy and read)

c. Yesterday, the leader asked people to goumai and yuedu the new version of the Constitution. (formal, to buy and read)

Generally, it is thought that the usage of "Verb + Verb" is not right in the field of Chinese grammar. But here the author (including readers) could not simply assert it because sentence c, with the same meaning, is quite acceptable in written language, while sentences $\mathrm{a}$ and $\mathrm{b}$ are barely acceptable in spoken language.

The paper shows from Example (1) that different styles with the same lexical meaning have different syntactic text representation, which, to some extent, inspires the reflection upon whether the commonly accepted syntactic rule is universally applicable.

Then the paper shows another two examples by FANG Mei (1994), in which some words are put at the end of a sentence to attract listeners' attention (see Examples (2)-(3)).

Example (2) Do not interrupt me, go or not go on earth, ni? (ni, Chinese pronunciation, you)

Example (3) Why don’t you speak, nice looking, Daoshi? (Daoshi, Chinese pronunciation, seldom in the end, means is or not)

These phenomena are seldom seen in formal written text like political articles. So some scholars believe that the grammar of written text is different from that of the spoken language (Brazil, 1995); and some scholars (FENG, 2011) have even coined a specific concept called "Style grammar" so as to serve the requirement of distinguishing styles, in which it is stated that grammar serves styles that in return contribute to grammar.

Actually, whether the grammars of spoken language and written language are two different grammars still need further discussion. But it is a fact that different styles indeed show some differences in texts.

\section{The Restraint on Genre Differences}

The genre here refers to narrative and non-narrative in general textual research. The non-narrative includes expositive text and argumentative text.

Previous scholars (LV, 1985) have noticed the differences of Chinese syntactic structure in different genres. For example, when distinguishing "you" sentence from "bei" sentence (you and bei, 由, 被, Chinese pronunciation, both mean by, but with their own distinctive usage), which can easily confound foreign students, 
LV Wen-hua said that "you" sentence is less widespread than "bei" sentence in frequency of use. But in very few articles, "you" sentence can also be used very centralized, for instance, in a report named "TV series Huo Yuanjia will be broadcast from today", there are 35 "you" sentences among the all 245 sentences. At the same time, the author also notices that "you" sentence enjoys high frequency in sports news and artistic performances, but "bei" sentence seems to be used more in texts conveying knowledge.

Nowadays, some scholars discriminate the similarities and differences between “yushi” (yushi, 于是, means then, so) and "suoyi" (suoyi, 所以, means so) (GUO, 2006) from the perspective of textual genre. For example:

Example (4) The red light turned on, suoyi/yushi (means so/then, so) our car stopped.

Both "suoyi" and "yushi" can be used here, but how do they differ with each other? The author believes that the essential difference is reflected by the fact that they highlight different textual characteristics of sentence groups or sentences. It is more appropriate to use "yushi" in simple narrative (see Example (5)).

Example (5) Early in the morning, we climbed to the top of the rear cab, lifted a roof, put the pedal on the sides of the bulkhead, and pedalled on them with the rudder in hands. Yushi/suoyi (means then/so) the boatman who was standing in the front of the boat took up the pole and shoved the boat off.

It is more appropriate to use "suoyi" (means so) in expositive text and argumentative text, in which traits and causes are emphasized (see Examples (6)-(7)).

Example (6) Her skin is smooth, but a little bit green, suoyi/Yushi (means so/then) it looks not so moist.

Example (7) It is good to get 60 points, suoyi/Yushi (means so/then) you should be happy.

Example (4) is not a simple text, so both of the terms are correct, but there are minor semantic differences. "yushi" (means then, so) narrates things simply, but "suoyi" (means so), meanwhile, highlights the reason for the car stopping.

Concerning the fact that genre affects syntax, FANG Mei (2007) also refers that because narrative is generally less involved in interactive communication, the temporal succession and agent orientation are the important components. Therefore, features of narrative text should be procedural and eventual. However, in non-narrative genre, such as dialogue, its key point is exchanging information and ideas, so the scene and the comment come to be the most important part. Therefore, in the author's opinion, this can explain the reason for the agentive object sentence (such as gebi ganmao le jige ren, 隔壁感冒了几个人, means several people next door have caught a cold), which can only be used in dialogue instead of narrative in Chinese.

It is obvious, in the above illustration, that, different genres, e.g., narrative, expositive, or argumentative text, have restraints on their syntactic project; in other words, genre has an influence on text. This may be the result of "genre priority principle" (ZHANG, 2006), in which it is stated that every text must belong to one genre, and every genre has a macro-semantic structure. The modes realizing these structures will be selected after the genre selection.

\section{The Restraint on Acquisition Mode Differences}

It is known that in the process of first language acquisition, children begin with single words and then make progress to two-word sentences. Finally, they reach the stage of simple sentences. The hierarchical system of 
language leads to the fact that the process of first language acquisition has its own rules. Children have the ability of assembling marks chain into a whole syntactic structure (ZHOU, 1999). When it comes to reading materials, the text must be ensured to be adapted to their ability for comprehension and in the meantime, the cohesion and coherence between syntactic structures should be recognized to guarantee a clear understanding of syntactic principles and semantic relations.

To make younger readers understand the text, the traits of "text" for children must differentiate from that for adults. Those differences can be grasped on lexical and syntactic level.

The following example for "children text" (see Example (8)), excerpted from a Chinese elementary school textbook, is a well-known story named "The Tadpoles Look for Their Mommy":

Example (8)

Yi tiao dayu you guolai le. (A big fish came over). The little tadpoles saw the fish had two big eyes and a big month. They (little tadpoles, but omitted in Chinese ) thought that the fish was their mommy. So, they followed her and cried: "Mommy, mommy."

"No, I'm not your mommy", the fish said with a smile, "I am little fish's mommy. Your mommy has four legs."

"Thank you! Thank you! We are going to look for our mommy." They were swimming around.

Yi zhi da wugui you guolai le. (A big tortoise came over). The little tadpoles saw that the tortoise had four legs. They (omitted in Chinese) thought she was their mother. So, they followed her and cried: "Mommy, mommy."

The tortoise smiled and said: "No, I'm not your mommy. I'm a tortoise. I am little tortoise' mommy. Your mommy has a big white belly."

"Thank you! We are going to look for our mommy. See you later."

"Good luck!" They went on swimming.

Yi zhi da bai'e you guolai le. (A big white goose came over). The little tadpoles saw its white belly. They (omitted in Chinese) thought happily that they found their mommy this time. So, they followed her and shouted: "Mommy, mommy."

The goose smiled and said: "Sorry, I'm not your mommy. I am little geese's mommy. Your mommy dresses in green and sings "gegege."

"Thank you! We are going to look for our mommy. See you later."

This is a story about little tadpoles seeking their mother for three times. In order to adapt to children's cognitive ability, the text demonstrates its distinctive characteristics.

Firstly, it lies in its simplicity of words organization. One word is repeated several times in the text, which reduces the difficulty of reading. Meanwhile, words such as "came over", "saw", "thought", "follow", and "mommy" have been used twice or three times as cohesion measures:

came over—saw — thought—follow—mommy

Secondly, the ellipsis in the following sentences has the same syntactic position with the subject of the first sentence and its explanation is constrained by parallelism principle (R. LI, SHI, \& HU, 2012).

Parallelism principle should meet the requirement that the omitted part should syntactically and semantically have the same meaning with the preceding part. The elliptical words can be easily reconstituted in accordance with that principle and children's cognitive ability. For instance, the omitted item "little tadpoles" can easily be restored in the subject position. Its semantic meaning agrees with "little tadpoles" in the sentence that precedes. The ellipsis will not become an obstacle of comprehension for children.

Thirdly, monotonous sentential patterns form the typical syntactic features. Nearly every sentence in this story follows a basic agent-action structure. All this simple sentences are connected into text and repeated for 
several times, adhering to the characteristics of children language acquisition, which include imitation, selective imitation (children choose to learn specific structures and contents spoken by adults), and syntactic assimilation (According to the generality of syntactic structures, language learners use learned structures to explore new sentences).

An "adult text", extracted from Rickshaw Boy by Lao She (see Example (9)), will be analyzed in comparison.

Example (9)

祥子的身上没有任何累赘, 一件灰色单军服上身, 和一条蓝布军裤, 都被汗沤得奇臭一自丛（）还没到他 身上的时候已经如此……闻着现在身上的臭汗味，他把以前的挣扎与成功看得分外光㭉，比原来的光荣放大了十 倍。他越想着过去便越恨那些兵们。他的衣服鞋帽, 洋车, 甚至于系腰的布带, 都被他们抢了去; （）只留给 他青一块紫一块的一身伤, 和满脚的疮!

Translation: Xiangzi was wearing only a thin gray tunic and a pair of blue cotton army trousers, both reeking of sweat and little more than rags - they'd been like that before he put them on. All he could think of were the white jacket and indigo-dyed lined pants he was wearing when they took them off him-they were so clean and so smart. There were nicer clothes than that in the world, but he knew how hard it had been for someone like him to be dressed that way. The sweat-stink of what he was wearing now reminded him of all he'd struggled for and made what he had accomplished seem nobler. The more he thought about his past, the deeper his hatred for the soldiers. They had taken his clothes, his shoes, his rickshaw, even the sash he used as a belt, in return for bruises and welts all over his body and blisters on his feet. (translated by Howard Goldblatt)

Compared to the "Child text", the structure of this story is apparently more complex.

Initially, "a thin gray tunic and a pair of blue cotton army trousers" is treated as subject in Chinese MS (The author discusses the novel according to Chinese MS, same as followings). On the contrary, when it is omitted, it is put after the preposition "cong" (从, means from) in the first brackets. What is more, the missing word in the second brackets is "they", substitute for "Those soldiers", "Those soldiers" is located in the subject position; however, "they" is placed as an object after the preposition "bei" (means passive voice).

In the light of syntax, this text not only includes sentences with structure of "agent-action", but also has other various syntactic structures such as "bă" sentence (subject + “把”, indicating the active voice, + object + complement, is usually a verbal phrase), "bèi” sentence (subject + “被”, indicating passive voice, + object + complement, is usually a verbal phrase), "bî" sentence (compare A with B). Due to abundant words and variations, this text becomes a colorful painting.

From the comparisons and contrasts between "Child Text" and "Adult Text", it is clear that acquisition differences also exert influence on lexical and syntactic structure in "Text".

\section{Practical Value of This Study}

Three aspects have been discussed on the register restraint in Chinese text, which is of great significance to teaching Chinese as a second language.

Firstly, for foreign learners in primary stage of Chinese, very colloquial, inverted sentences and sentences which are similar to the syntactic features should not be taught in spoken classes.

Secondly, some questions in Chinese grammar should be explained in the context of characteristics of genre; otherwise, minor usage differences will be hard to distinguish. 
Finally, instead of in the pursuit of famous authors' novels with complex sentences and word organization, the appropriate texts chosen as materials for Chinese children, are more suitable for foreigners of primary level. It will lower learning difficulties and thus lead to an effective acquisition.

\section{Conclusion}

It is the fact that different styles indeed show some differences in texts, and different structures. These structures will be selected after the genre selection.

Comparing "Child Text" and "Adult Text", it is clear that acquisition differences also exert influence on lexical and syntactic structure in "Text".

Some questions in Chinese grammar should be explained in the context of characteristics of genre, otherwise, minor usage differences will be hard to distinguish.

\section{References}

Brazil, D. (1995). A grammar of speech. Oxford: Oxford University Press.

CHEN, W. (1979). An introduction to rhetoric. ShangHai: ShangHai Education Press.

FANG, M. (1994). Subject-predicate structure of spoken Chinese. Journal of Peking University (Humanities and Social Sciences), 2, 66-75.

FANG, M. (2007). The stylistic motivation to syntax shaping. Rhetoric Learning, 6, 1-7.

FENG, S. (2011). Style grammar and its literary functions. Contemporary Rhetoric, 4, 1-13.

GUO, J. (2006). The similarities and differences of "yushi" and "suoyi". Chinese Linguistics, 4, 27-34.

Halliday, M. A. K. (1985). An introduction to functional grammar. London: Edward Arnold.

LI, R., SHI, D., \& HU, J. (2012). The research of omitted structure of children's language acquisition. Studies of the Chinese Language, 3, 211-224.

LI, X. (2005). A study of the definition of style. Fudan Journal (Social Sciences Edition), 2, 176-196.

LIU, D. (1994). The style is a type of verbal behavior. Rhetoric Learning, 3, 1-3.

LV, W. (1985). “you” sentence and "bei”sentence. Language Teaching and Linguistic Studies, 2, 17-28.

TIAN, R. (2010). A study of the restraint of text on syntax. Journal of Yunnan Normal University (Teaching and Research on Chinese as a Foreign Language), 4, 13-16.

ZHANG, D. (2006). A study of macro-principle on textual coherence. Foreign Languages and Their Teaching, 10, 7-13.

ZHOU, G. (1999). A study of children's language acquisition theory. Chinese Teaching in the World, 3, 77-83.

ZHU, Y. (1987). A study about register. Shandong Foreign Language Teaching Journal, 4, 24-28. 